\title{
A Multi-Port Bidirectional Power Conversion System for Reversible Solid Oxide Fuel Cell Applications
}

\author{
Lin, Xiang; Sun, Kai; Lin, Jin; Zhang, Zhe; Kong, Wei
}

Published in:

Proceedings of 2018 International Power Electronics Conference

Link to article, DOI:

10.23919/IPEC.2018.8507566

Publication date:

2018

Document Version

Peer reviewed version

Link back to DTU Orbit

Citation (APA):

Lin, X., Sun, K., Lin, J., Zhang, Z., \& Kong, W. (2018). A Multi-Port Bidirectional Power Conversion System for Reversible Solid Oxide Fuel Cell Applications. In Proceedings of 2018 International Power Electronics Conference (pp. 3460-3465). IEEE. https://doi.org/10.23919/IPEC.2018.8507566

\section{General rights}

Copyright and moral rights for the publications made accessible in the public portal are retained by the authors and/or other copyright owners and it is a condition of accessing publications that users recognise and abide by the legal requirements associated with these rights.

- Users may download and print one copy of any publication from the public portal for the purpose of private study or research.

- You may not further distribute the material or use it for any profit-making activity or commercial gain

- You may freely distribute the URL identifying the publication in the public portal 


\title{
A Multi-Port Bidirectional Power Conversion System for Reversible Solid Oxide Fuel Cell Applications
}

\author{
Xiang $\operatorname{Lin}^{1}$, Kai Sun ${ }^{1 *}$, Jin Lin ${ }^{1}$, Zhe Zhang ${ }^{2}$ and Wei Kong ${ }^{3}$ \\ 1 State Key Lab of Power Systems, Department of Electrical Engineering, Tsinghua University, Beijing, China \\ 2 Department of Electrical Engineering, Technical University of Denmark, Kgs. Lyngby, Denmark \\ 3 Department of Electric Power Engineering, Shanghai University of Electric Power, Shanghai, China \\ *E-mail: sun-kai@mail.tsinghua.edu.cn
}

\begin{abstract}
Reversible Solid Oxide Fuel Cell/Electrolyser Cell (SOFC/EC) technology is an attractive solution for high energy storage system in the utility grid. However, the wide range of voltage and low power of single SOFC/EC stack make it difficult to design the power conversion system for SOFC/EC storage system. In this paper, a new power multiport bidirectional conversion system is proposed to connect multiple SOFC/EC stacks with the utility grid. The converter structure contains a multi-port structure with two conversion stages. The two-stage conversion structure is first analyzed to address the wide-range of SOFC/EC stack's voltage. The high-step-down CLLC resonant converter is implemented to achieve efficient voltage transformation, and the interleaved buck converter is employed as the second stage to control the voltage of SOFC/EC stack within a wide range. The derivation of the multi-port structure is introduced, and the control strategy of proposed conversion system is also discussed in this paper. The proposed conversion system enables a flexible control for the application of multiple SOFC/EC stacks. The feature of the proposed system is verified by the experiments from a down-scale prototype.
\end{abstract}

Keywords-multi-port bidirectional power conversion system, reversible solid oxide fuel cell, CLLC resonant converter, interleaved buck converter

\section{INTRODUCTION}

With the advent of renewable energy, there is a strong demand for high power storage system in the power grid. The hydrogen storage system is an attractive solution of the high-power storage system for several reasons: 1) Hydrogen is a clean energy and has the highest energy density $(\mathrm{KWh} / \mathrm{Kg})$; 2) Hydrogen storage system is one of few choices for long-term storage; 3) Hydrogen storage system can be extended to high power system [1]. Recently, the Solid Oxide Fuel Cells can operate as Electrolyser Cells to generate hydrogen, which makes this Solid Oxide Fuel Cell/Electrolyser Cell (SOFC/EC) technology more attractive compared to separated water electrolyser and fuel cells [2-3]. To connect the SOFC/EC with the utility grid, high power bidirectional conversion system is needed. Traditionally, the conversion system has two conversion stages consisting of a dc-dc converter to connect distributed storage stacks with a dc bus, and a centralized dc-ac converter to connect the dc bus to the utility grid. This paper focuses on the dc-dc conversion stage which is usually designed with the consideration of SOFC/EC stack's characteristics.

However, the SOFC/EC has certain electrical characteristics which complicate the power conversion system design. Firstly, because of the challenge to equalize fuel/gas-pressure within the cells, a single SOFC/EC stack has a limited number of cells resulting in low stack voltage [4]. So, to improve the system's power capacity, a multi-port conversion system is needed to connect multiple SOFC/EC stacks. Moreover, the conversion system should achieve high step-down voltage transformation. Secondly, the SOFC/EC has a wide operating voltage, and keeping interfacing converter high efficiency over such a wide range is a challenge.

Therefore, to design an efficient power conversion system for SOFC/EC, both the system structure and converter topology need to be addressed. Alternatively, storage stacks can be connected in series directly [5-6]. However, in such a structure, it is difficult to adjust the operation of each stack independently for a higher system efficiency and one stack failure may affect the operation of the whole string. In some literatures, storage stacks are connected in a cascaded structure with isolated dc-dc converters [7]. Such a structure has an improved control flexibility, but the control complexity is high over a wide voltage range. In recent years, multi-port structures also attract an increasing attention because of its ability to connect multiple sources. However, those systems usually have non-modular structure and complex control strategy and thereby are not suitable for utility-scale energy storage system [8]. Regarding to converter topologies, several topologies for unidirectional fuel cell have been proposed [9-13], among which dual-activebridge (DAB) converter and isolated boost converter are the most popular ones for high-step-down voltage conversion. But auxiliary circuits are usually needed to extend voltage range of the DAB converter or to achieve ZVS for the isolated boost converter.

In this paper, a new multi-port bidirectional power conversion system is proposed as shown in Fig.1. The interleaved buck converter converts the wide-range voltage of SOFC/EC to nearly constant voltage at the middle stage, and the multi-port CLLC resonant bidirectional converter (CLLC-RBC) connects multiple 
sources with the dc bus. With such arrangement, a flexible and simplified control of each stack is achieved, as well as the power capacity can be easily extended.

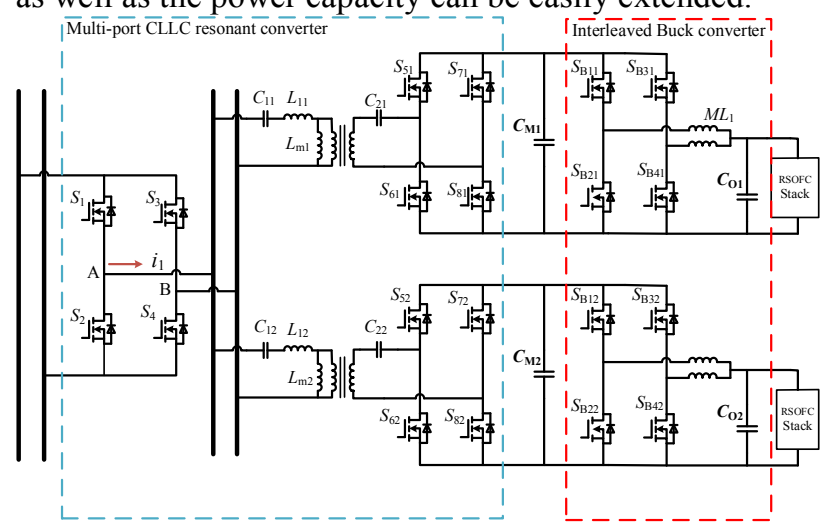

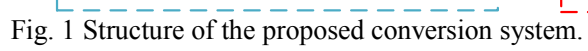

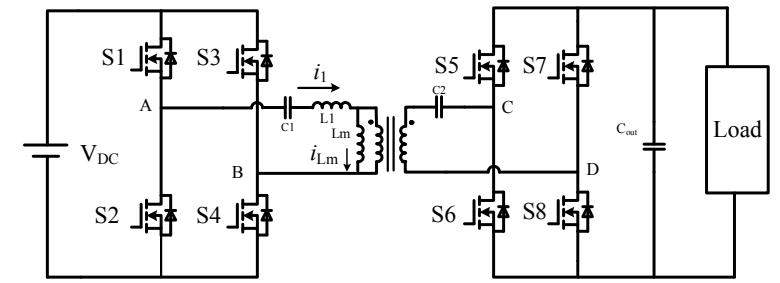

Fig. 2. CLLC-RBC topology.

In the following sections of the paper, the single-inputmulti-output CLLC-RBC and interleaved buck converter are discussed. The operation of system is also analyzed. Finally, the experimental results are presented to verify the operation of system.

\section{PROPOSED CONVERSION SYSTEM}

\section{A. Two-stage structure for CLLC-RBC application}

In recent years, CLLC-RBC has become a desirable topology for bidirectional dc-dc applications due to its simple control, high-frequency operation and high efficiency [14-15]. A typical CLLC-RBC topology is shown in Fig. 2, and the frequency modulation scheme is usually employed. In the forward mode, in which power is delivered from the high-voltage DC bus to the load, the switches $S 1 \& S 4$ and $S 2 \& S 3$ are driven by complementary signals with $50 \%$ duty cycle while all the switches at low voltage side are turned off or are controlled in synchronous rectification mode. However, in the reverse mode, the switches $S 5 \& S 8$ and $S 6 \& S 7$ are driven by complementary signals with $50 \%$ duty cycle, and the switches at high voltage side are turned off or are controlled in synchronous rectification mode. The ZVS is achieved with the assistance of the magnetic excitation current $i_{\mathrm{Lm}}$. The voltage gain of the CLLC resonant converter is usually analyzed with the approach of fundamental mode, and a typical voltage gain curve in forward mode (SOEC) is presented in Fig. 3.

While employing CLLC resonant converter for SOFC/EC applications, the wide stack voltage needs to be addressed. Because of the polarization of SOFC/EC, the stack voltage changes with current.

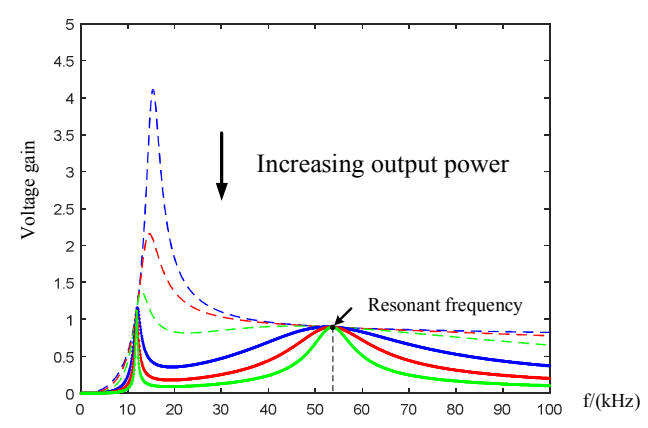

Fig. 3 Typical voltage gain of the CLLC resonant converter in forward mode.

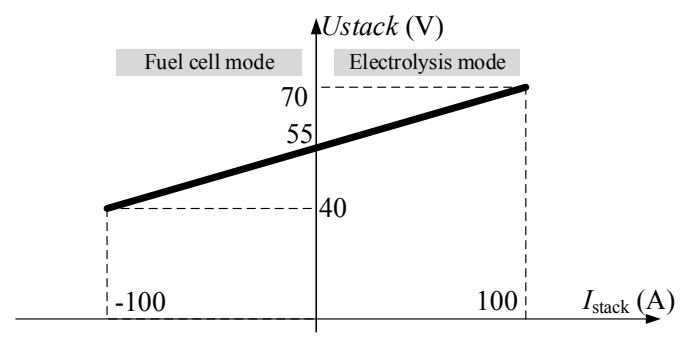

Fig. 4 Simplified U-I curve of SOFC/EC stacks.

A simplified steady-state U-I curve of a SOFC/EC stack is shown as an example in Fig. 4, where the voltage varies from $40 \mathrm{~V}$ to $70 \mathrm{~V}$, and the maximum power is 7 $\mathrm{kW}$ and $4 \mathrm{~kW}$ in SOEC and SOFC modes, respectively. The following evaluation is based on this example. Therefore, such a wide voltage range set a difficulty to design an efficient dc-dc converter.

In the previous literature, the application of resonant dc-dc converter contains two different approaches: single-stage and two-stage structure [14-16]. In singlestage structure, the frequency of CLLC-RBC is adjusted to control the voltage gain, and in two-stage structure, the resonant dc-dc converter is controlled with fixed frequency and a non-isolated dc-dc converter is employed to adjust the voltage gain. But for SOFC/EC application, the single-stage structure is not suitable. The voltage gain curve in Fig. 3 indicates that the voltage gain is related to the output power, and in light load, higher voltage gain is easier to be achieved. However, Fig.4 indicates that higher voltage gain is needed in heavy load condition during forward mode. So, if the single-stage structure is employed for SOFC/EC stacks, it is difficult to design the resonant tank and the operation frequency range.

On the other hand, the two-stage structure, as illustrated in Fig.5 is suitable for SOFC/EC application. Fig.4 indicates that the CLLC-RBC has stable voltage gain at resonant frequency in different load condition. Therefore, by controlling frequency of CLLC resonant converter at the fixed resonant frequency, it is much simplified to design the control strategy and converter parameters. The bidirectional interleaved buck converter is chosen to assist the adjustment of operation voltage. Since the CLLC resonant converter has achieved highstep-down voltage transformation, the required voltagegain (duty cycle) range of interleaved buck converter is 
reduced and low voltage-gain is avoided (because the switching loss is related to dc voltage at the high-voltage side and dc current at the low voltage side, and the extreme low voltage gain, for example 0.1 , will cause large switching loss). In the meantime, comparing with buck converter, interleaved buck converter has smaller switching and conduction loss with equal output current ripple.

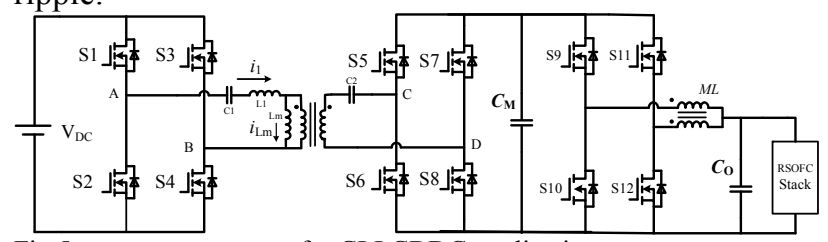

Fig.5 two-stage structure for CLLCBDC application

\section{B. Multi-port structure derivation}

By above analysis, the two-stage dc-dc converter is suitable for single SOFC/EC stack. For power storage system, a few of such stacks are needed. Because of the application of CLLC-RBC, a new system structure to connect multiple RSOFC stacks is designed as Fig. 1 shows. Traditionally, to connect several SOFC/EC stacks to the dc bus, several dc-dc converters are needed. But in the proposed conversion system, the multi-port structure is applied instead. In the two-stage dc-dc converter, the CLLC resonant converter is controlled at resonant frequency, so different CLLC resonant converters have same drive signals for corresponding switches while they have same resonant tank parameters. For each converter, the current at the high voltage side is relative low, so it is practical to integrate several full bridge circuits at the high voltage side into one full bridge circuit at the high voltage side as shown in Fig.6. Through this structure, multi-port capacity is achieved with reduced number of active switches. Also comparing with multi-port structure with multi-winding transformer, the design of resonant tank and the isolated transformer are much simplified.

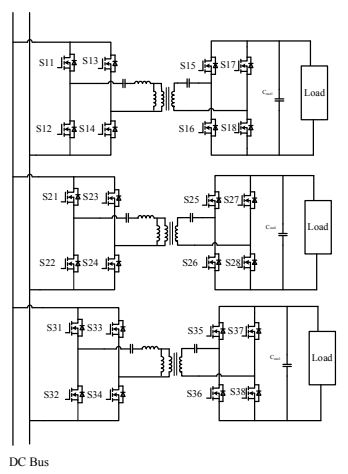

(a)

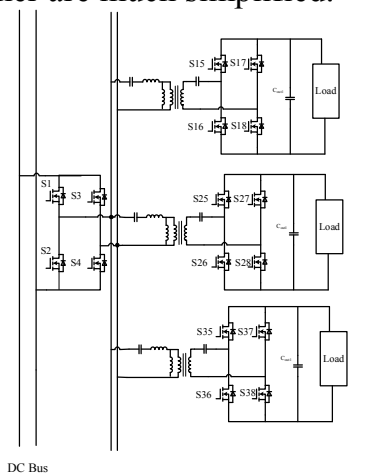

(b)
Fig. 6 Comparison of different structures to connect multiple sources (a) parallel-operated structure, (b) integrated structure

Since the frequency of multi-port CLLC-RBC is fixed, the output power is adjusted by the interleaved buck converter in the two-stage converter. Because the combination of the full bridge circuits does not cause the couple of different stacks power, the proposed multi-port structure enables a flexible control of each stack. The voltage of each stack can be adjusted without affect other stacks. This is the salient benefit of proposed multi-port conversion system. As shown in Fig.7, in the past research of high power storage system, the storage stacks are usually connected in series or with a cascaded structure. In the series-connected structure, the failure of one storage stack will affect other stacks. In the cascaded structure, each dc-dc converter shares the same current in the high-voltage side, so the power of each stack is coupled. With the constant voltage of dc bus, the power adjustment of one storage stack will affect the common current in the high-voltage side and then the operation of other storage stacks.

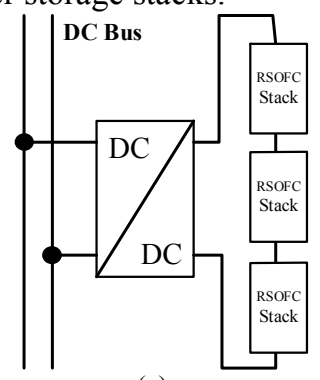

(a)

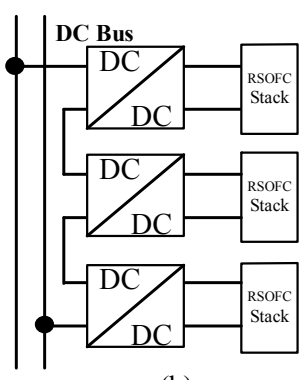

(b)
Fig. 7 tradition storage system structure: (a) series-connected structure; (b) cascaded structure.

The proposed conversion system has an extensible structure and is suitable for storage system at different power rate. For high power storage system, the proposed conversion system could be designed as a modular storage block, and the power of storage system can be scaled by connecting several blocks in parallel structure as Fig. 8 shows.

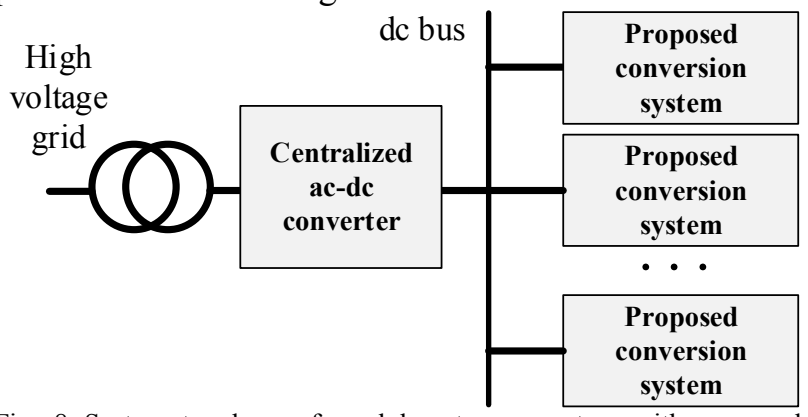

Fig. 8 System topology of modular storage system with proposed conversion system

\section{CONTROL OF THE PROPOSED CONVERSION SYSTEM}

In Section II, the structure of proposed conversion system is fully evaluated and, in this section, the control strategy is further analyzed. The following analysis is based on the single-input-dual-output system as shown in Fig.1.

The switching frequency of multi-port CLLC resonant converter is fixed at the resonant frequency, so the voltage of the middle stage is constant under different load condition. To limit the voltage gain of the interleaved buck converter, the middle stage voltage $V_{\text {middle }}$ is designed to be a little higher than the maximum voltage of a single SOFC/EC stack $V_{\text {stack max: }}$ $V_{\text {middle }}=1.1 V_{\text {stack_max. }}$ For example, for the stack shown in Fig.3, the middle stage voltage is designed at $80 \mathrm{~V}$. Then the voltage gain range of interleaved buck converter is 
$0.5-0.875$. Because the middle stage voltage is constant, the control of interleaved buck converter is much simplified. As shown in Fig. 9, by controlling the duty cycle D of interleaved buck converter, the current (or voltage) of a single stack is regulated in forward and reverse mode.

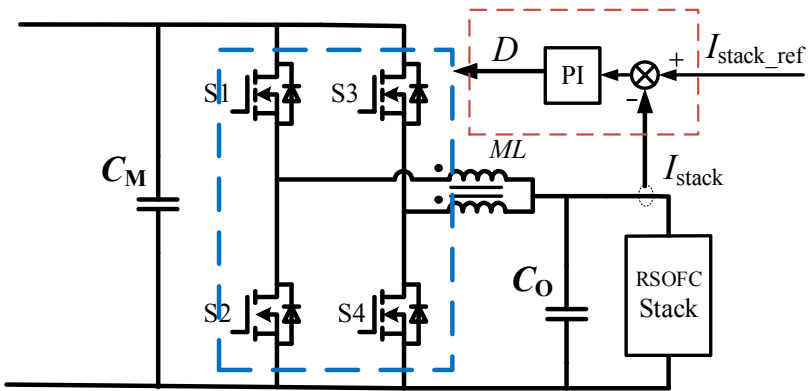

Fig. 9 Control diagram for the interleaved buck converter.

The control diagram of the whole conversion system is presented in Fig.10. The control target is the system power. By measuring the current from dc bus, the power of the entire system can be calculated. Based on an allocation mechanism, the current reference $I_{\text {ref }}$ of each stack is calculated. Therefore, the current of each stack is regulated. The allocation of current references can be set to different rules under different load conditions. Because the control of different ports is decoupled, the current references can be adjusted flexibly under different condition to improve the performance of the entire system. For example, in the light load condition, the current reference of the port $\# 2$ can be set to 0 to improve the system efficiency. In the heavy load condition, the current reference of each port is set to be equal to realize power requirement.

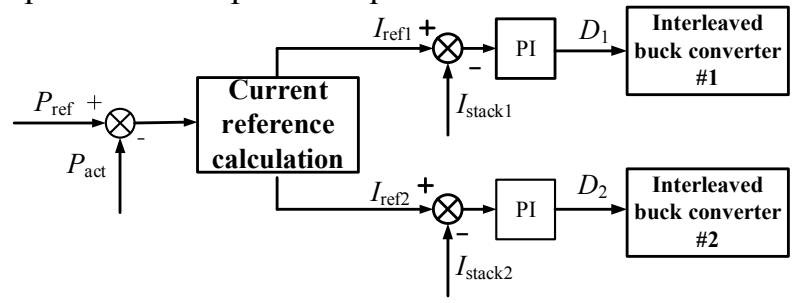

Fig. 10 the control diagram for the conversion system

A single-input-dual-output system (Fig.1) is built in the MATLAB/Simulink to illustrate the flexible operation of proposed power conversion system. The parameters of resonant tanks and mutual inductance in interleaved buck converter are shown in Table 1 . The voltage of dc bus is set to $600 \mathrm{~V}$, and the input voltage of middle stage $V_{\mathrm{Ck}}$ is designed to around $80 \mathrm{~V}$. The SOFC/EC stacks are simulated with the controllable current sources, and the U-I curve of the controllable current sources is programmed as Fig. 4 to simulate the stacks' characteristics.

TABLE 1 Parameters of resonant tank and mutual inductance

\begin{tabular}{|c|c|c|c|c|c|}
\hline$L_{11 \& 12}$ & $C_{11 \& 12}$ & $C_{21 \& 22}$ & $L_{\mathrm{m} 1 \& \mathrm{~m} 2}$ & $L_{\mathrm{ML} 1 \& 2}$ & $M_{\mathrm{ML} 1 \& 2}$ \\
\hline $150 \mathrm{uH}$ & $100 \mathrm{nF}$ & $8000 \mathrm{nF}$ & $550 \mathrm{uH}$ & $100 \mathrm{uH}$ & $-34 \mathrm{uH}$ \\
\hline
\end{tabular}

The example situation is that both stacks work at the fuel cell mode, and the power demand for the conversion system is increased from light load to heavy load. As illustrated in Fig.11, the current of each stack can be adjusted flexibly without affecting the other stack. The demand of power is addressed with one stack in light load and two stacks in heavy load. So in different load condition, the conversion system can adjust its load distribution for better system efficiency.

The simulation illustrates that the proposed system conversion system enables a flexible control of connected storage stacks. This is an advantage comparing to traditional storage structures as shown in Fig. 7. Such flexible control is achieved because of the application of multi-port CLLC-RBC. In the meantime, the system parameters, especially the parameters of resonant tanks, are easy to design, because no integration of resonant tanks is needed in the proposed structure.

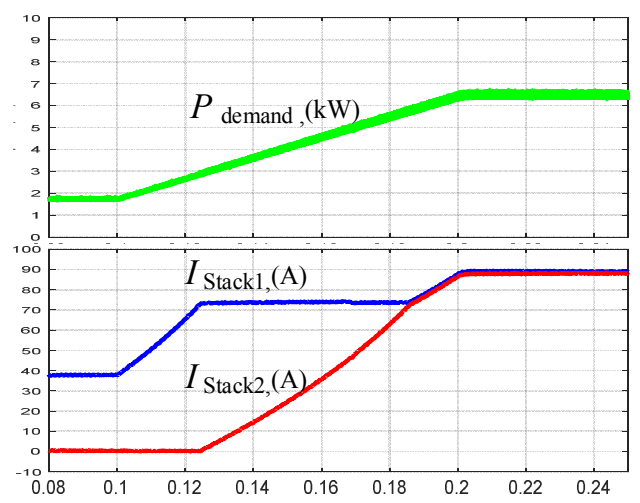

Fig. 11 the control diagram for the conversion system

\section{EXPERIMENT RESULTS}

To verify the flexible control of the system, a reduced-scale prototypes of proposed conversion system has been designed and built as shown in Fig. 12 . The conversion system contains two output ports. The SiC MOSFET C2M0080120D and Si MOSFET IRFP4127PbF are used as the switches at high voltage and low voltage side respectively. The design parameters of resonant tanks and mutual inductors are listed in Table 1. The switching frequency of CLLC resonant converter is set to $50 \mathrm{kHz}$, and the frequency of interleaved buck converter is set to $20 \mathrm{kHz}$.

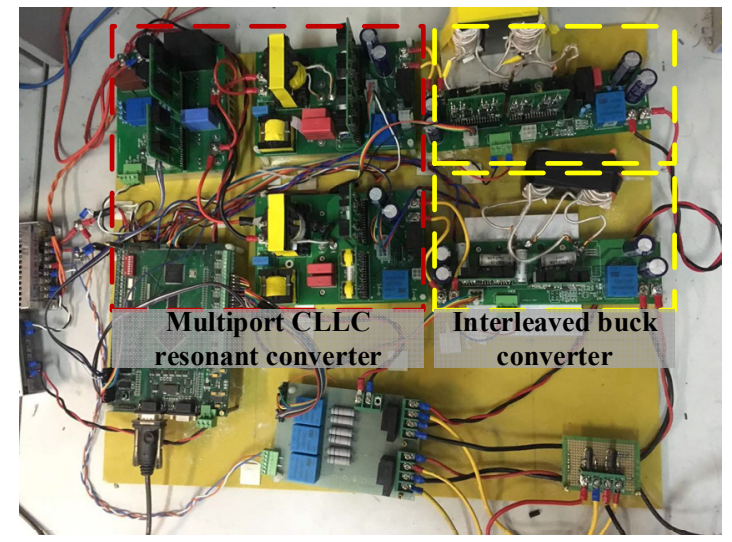

Fig. 12 the prototype of proposed conversion system. 
First, the forward-mode operation is verified, and the resistors $(5 \Omega)$ are used as the load to simulate the SOFC stacks. The input voltage is set to $200 \mathrm{~V}$, and the voltages of output ports are set as follow: $u_{\mathrm{o} 1}=20 \mathrm{~V}, u_{\mathrm{o} 2}=18 \mathrm{~V}$. The steady-state waveforms are shown in Fig. 13. The input current of each resonant tank is shown in Fig.13 (a), and two resonant tanks share the same input ac square voltage waveform. In Fig.13 (b), two interleaved buck converters are controlled with different duty cycles. The experiment waveforms indicate that the output voltages $v_{\mathrm{o} 1} \& v_{\mathrm{o} 2}$ can be set to different status, and the parameter differences of resonant tanks or mutual inductors don't affect operation of the proposed system. The combination of full bridge circuit at the high voltage side doesn't affect the independent control of $u_{\mathrm{o} 1} \& u_{\mathrm{o} 2}$.

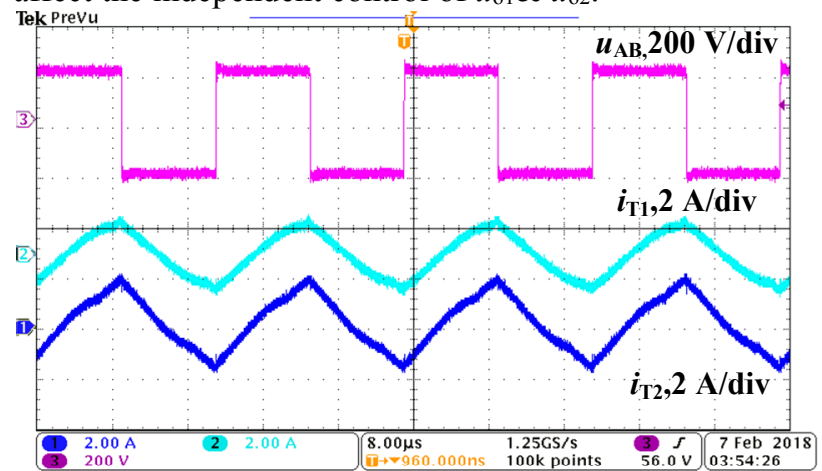

(a)

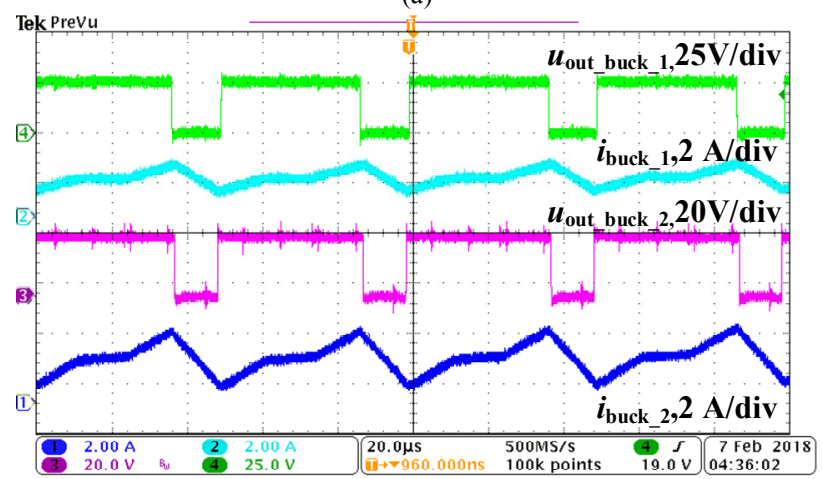

(b)

Fig. 13 Experiment results of steady state: (a) waveforms of input currents of two transformers; (b) waveforms of two interleaved buck converters.

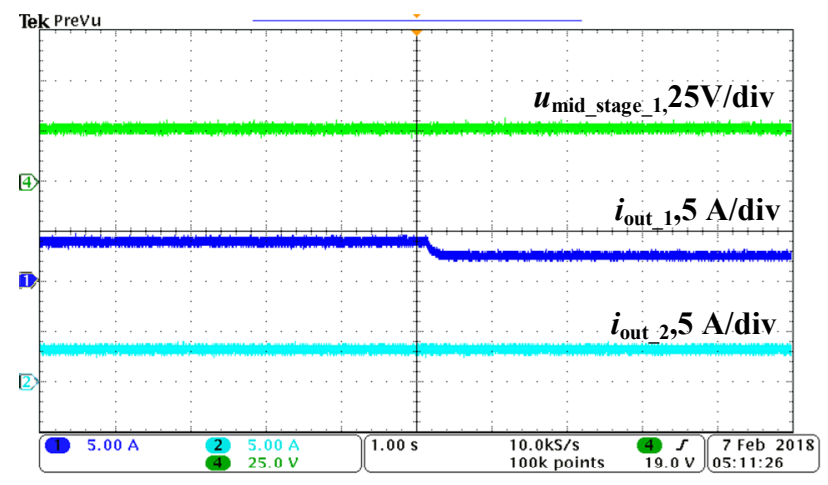

Fig. 14 the experiment results of dynamic process

The experiment of dynamic performance is also conducted. The input voltage is set to $200 \mathrm{~V}$, and $u_{\mathrm{o} 2}$ is set to $18 \mathrm{~V}$. The voltage reference of $u_{\mathrm{o} 1}$ is changed from $20 \mathrm{~V}$ to $12 \mathrm{~V}$. The experiment waveform is shown in Fig. 13. The output currents are shown in the result. By controlling the duty cycle of the interleaved buck converters, the control of $i_{\text {out_ } 1}$ is achieved and the change of $i_{\text {out_1 }}$ doesn't affect $i_{\text {out_2 }}$. Therefore, in the proposed conversion system, each port at the lowvoltage side can be controlled independently.

The back-mode operation is conducted as well. The resistor $(500 \Omega)$ is connected to the high-voltage side, and two dc sources are connected to two low-voltage ports. The experiment results of steady state and transient state are presented in Fig. 14 and Fig. 15. The voltage of port $\# 1$ is set to $20 \mathrm{~V}$ and the voltage of port \#2 is set to $15 \mathrm{~V}$. The waveforms indicate that the allocation of each port's power could be adjusted flexibly without affecting the total power of the conversion system.

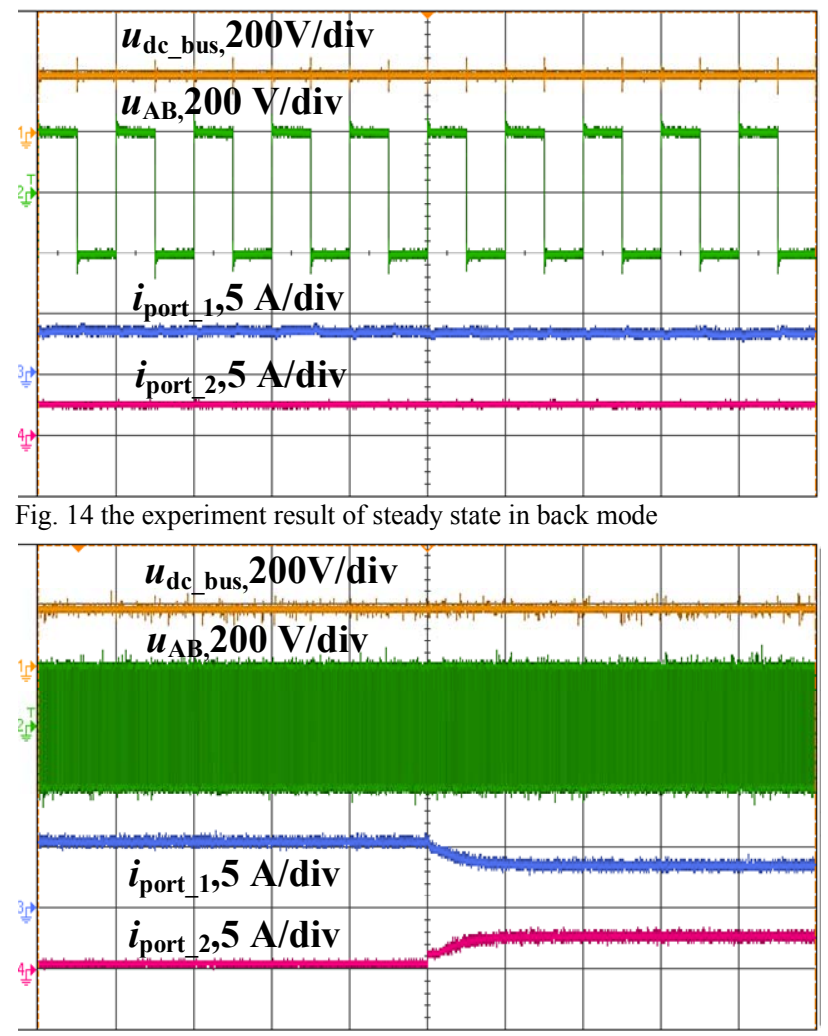

Fig. 15 the experiment result of transient state in back mode

The above experimental results illustrate that the proposed conversion system can achieve flexible control in both forward-mode and back-mode operation. From the angle of control, the proposed conversion system can be seen as two separate converters. And such feature is based on the two-stage conversion structure with CLLCRBC. In the storage system with SOFC/EC stacks, such ability can enable better performance for the whole conversion system and each stack. This is a salient advantage of proposed conversion system comparing to traditional structure for high power storage system.

\section{CONCLUSION}

In this paper, a new multi-port bidirectional conversion 
system is proposed to connect multiple SOFC/EC stacks with utility grid. With the analysis of CLLC-RBC's feature, the two-stage conversion structure is applied for the application of SOFC/EC. By the combination of full bridge circuit at high-voltage side, the multi-port CLLC$\mathrm{RBC}$ is designed to achieve high-step-down voltage transformation with fixed frequency control, and the interleaved buck converter is employed to control the output voltage. The control of the proposed conversion system is illustrated in this paper, and the propose conversion system enables a more flexible control comparing to traditional storage system structures. A reduced-scale single-input-dual-output prototype is built and the flexible control is verified with the prototype.

\section{ACKNOWLEDGMENT}

The authors would like to acknowledge the supports by National Key Research and Development Program (2016YFE0102600) and State Key Lab of Power Systems, Tsinghua University (SKLD16Z04).

\section{REFERENCES}

[1] Luo, Xing, et al. "Overview of current development in electrical energy storage technologies and the application potential in power system operation." Applied Energy 137 (2015): 511-536.

[2] Schiebahn S, Grube T, Robinius M, et al. Power to gas: Technological overview, systems analysis and economic assessment for a case study in Germany[J]. International journal of hydrogen energy, 2015, 40(12): 4285-4294.

[3] Ni M, Leung M K H, Leung D Y C. Technological development of hydrogen production by solid oxide electrolyzer cell (SOEC)[J]. International Journal of Hydrogen Energy, 2008, 33(9): 2337-2354.

[4] Pittini, Riccardo, Zhe Zhang, and Michael AE Andersen. "Isolated full bridge boost DC-DC converter designed for bidirectional operation of fuel cells/electrolyzer cells in grid-tie applications." Power Electronics and Applications (EPE), 2013 15th European Conference on. IEEE, 2013.

[5] Lang P, Michel $M$, Wade $N$, et al. Dynamic energy storage-A UK first[J]. 2012.

[6] Krishnamoorthy H S, Rana D, Garg P, et al. Wind turbine generator-battery energy storage utility interface converter topology with medium-frequency transformer link[J]. IEEE Transactions on Power Electronics, 2014, 29(8): 4146-4155

[7] Bragard M, Soltau N, Thomas S, et al. The balance of renewable sources and user demands in grids: Power electronics for modular battery energy storage systems[J]. IEEE Transactions on Power Electronics, 2010, 25(12): 3049-3056.

[8] Hawke, Joshua T., Harish S. Krishnamoorthy, and Prasad N. Enjeti. "A family of new multiport power-sharing converter topologies for large grid-connected fuel cells." IEEE Journal of Emerging and Selected Topics in Power Electronics 2.4 (2014): 962-971

[9] Wang, Jin, et al. "Low cost fuel cell converter system for residential power generation." IEEE transactions on Power Electronics 19.5 (2004): 1315-1322.

[10] Zhang, Zhe, et al. "Analysis and design of a bidirectional isolated DC-DC converter for fuel cells and supercapacitors hybrid system." IEEE transactions on Power Electronics 27.2 (2012): 848-859.

[11] Nymand, Morten, and Michael AE Andersen. "Highefficiency isolated boost DC-DC converter for high-power low-voltage fuel-cell applications." IEEE Transactions on Industrial Electronics 57.2 (2010): 505-514.

[12] Prasanna, U. R., and Akshay K. Rathore. "Extended range ZVS active-clamped current-fed full-bridge isolated DC/DC converter for fuel cell applications: analysis, design, and experimental results." IEEE Transactions on Industrial Electronics 60.7 (2013): 2661-2672.

[13] Rathore, Akshay K., Ashoka KS Bhat, and Ramesh Oruganti. "Analysis, design and experimental results of wide range ZVS active-clamped LL type current-fed DC/DC converter for fuel cells to utility interface." IEEE Transactions on Industrial Electronics 59.1 (2012): 473485.

[14] Chen W, Rong P, Lu Z. Snubberless bidirectional dc-dc converter with new CLLC resonant tank featuring minimized switching loss[J]. IEEE Transactions on industrial electronics, 2010, 57(9): 3075-3086.

[15] Zahid Z U, Dalala Z M, Chen R, et al. Design of bidirectional $\mathrm{dc}-\mathrm{dc}$ resonant converter for vehicle-to-grid (V2G) applications[J]. IEEE Transactions on Transportation Electrification, 2015, 1(3): 232-244.

[16] Krismer F, Biela J, Kolar J W. A comparative evaluation of isolated bi-directional DC/DC converters with wide input and output voltage range[C]//Industry Applications Conference, 2005. Fourtieth IAS Annual Meeting. Conference Record of the 2005. IEEE, 2005, 1: 599-606. 